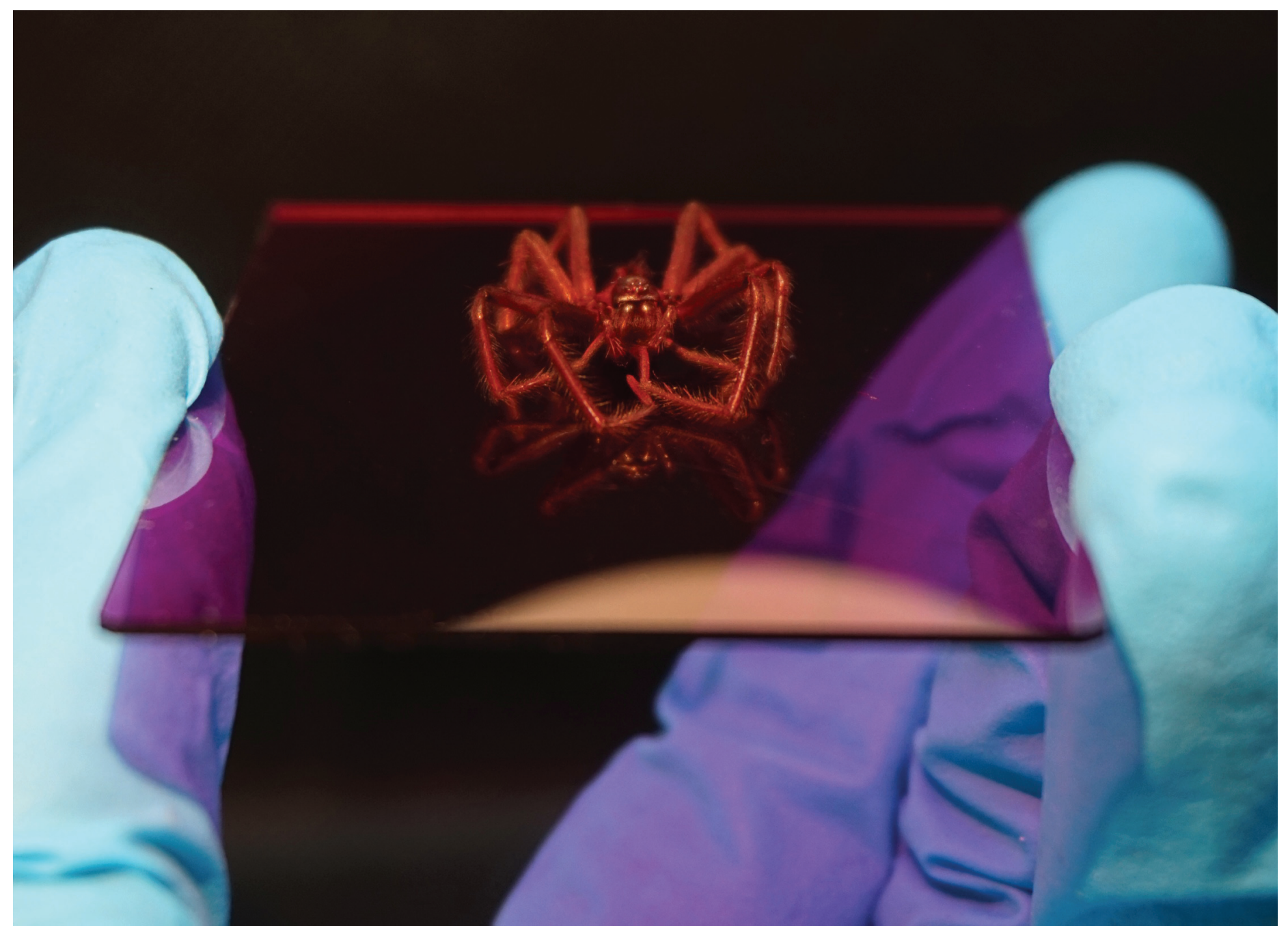

Showcasing research from Professor Ola Nilsen's laboratory, Department of Chemistry, University of Oslo, Norway.

Quinizarin: a large aromatic molecule well suited for atomic layer deposition

The optically active hydroxyanthraquinones have proven well suited as volatile and reactive molecules for the formation of hybrid films by atomic/molecular layer deposition. We use it as a tool for designing optical coatings by exploiting extended aromaticity. One of these molecules, the orange dye molecule quinizarin, is combined with trimethylaluminium to produce a deep pink coating with strong optical absorption. Its low deposition temperature of $175^{\circ} \mathrm{C}$ allows coating of even fragile and temperaturesensitive organic substrates, illustrated by coating a self-dead spider.

\section{As featured in:}

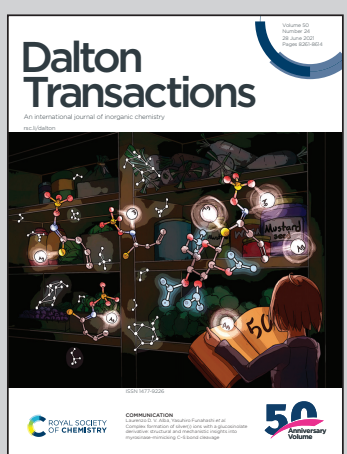

See Per-Anders Hansen and Ola Nilsen, Dalton Trans., 2021, 50, 8307. 


\section{(A) Check for updates}

Cite this: Dalton Trans., 2021, 50 8307

Received 1st March 2021, Accepted 23rd April 2021

DOI: $10.1039 / \mathrm{d} 1 \mathrm{dt} 00683 \mathrm{e}$

rsc.li/dalton

\title{
Quinizarin: a large aromatic molecule well suited for atomic layer deposition $\uparrow$
}

\author{
Per-Anders Hansen (iD) and Ola Nilsen (iD) *
}

\begin{abstract}
Atomic layer deposition (ALD) is a remarkable synthesis tool due to the vast array of materials that can be deposited and the complexity of structures that can be designed. The low-temperature layer-by-layer approach even allows organic and inorganic components to be combined as hybrid or composite materials. The technique is then called molecular layer deposition (MLD). This opens the door for deposition of advanced optical materials using highly absorbing aromatic molecules. Unfortunately, most large aromatic molecules are difficult to sublime or have insufficient reactivity. This is a major barrier for ALD when designing with the use of organic components for dye-sensitized solar cells, luminescence, visible light photochemistry, chemical sensors and organic electronics. In this work, we introduce a well-known orange dye molecule, quinizarin. This molecule has a large conjugated aromatic system with strong absorption of visible light and shows strong luminescence both in solutions and as a complex together with aluminium ions. Interestingly, quinizarin also shows surprisingly good properties for film deposition due to reactive $-\mathrm{OH}$ groups and low sublimation temperature $\left(130^{\circ} \mathrm{C}\right)$. Strongly coloured pink hybrid films were deposited with trimethylaluminium and quinizarin at $175^{\circ} \mathrm{C}$ with a growth rate of $0.28 \mathrm{~nm}$ per cycle. These films were not luminescent although their optical absorption spectra are similar to those of the corresponding solution. An attempt was made to dilute quinizarin through partial replacement with pentaerythritol as a multilayer structure or simultaneous co-pulsing, although this also did not produce luminescent films. The low sublimation temperature, good reactivity and large conjugated system of quinizarin open the way for exploration of solid-state hybrid and organic films based on this molecule along many different technological pathways.
\end{abstract}

\section{Introduction}

Atomic layer deposition (ALD) is a remarkable synthesis tool capable of producing a vast array of materials from inorganic, ${ }^{1}$ quaternary ${ }^{2}$ and even quinary compounds, ${ }^{3}$ nanostructures, ${ }^{4}$ organic-inorganic hybrids, ${ }^{5}$ crystalline $\mathrm{MOF}$ films ${ }^{6}$ and pure organic compounds. ${ }^{7}$ ALD is also often named molecular layer deposition (MLD) when organic molecules are introduced as a building block into organic-inorganic hybrid or purely organic film materials. The low temperature and layer-by-layer approach limits the interdiffusion between layers and enables a wide range of combinations of different material classes at the sub-nanometer scale. This gives rise to completely new possibilities in designing with combinations of material properties $^{8}$ and to control optical and electronic interactions. ${ }^{9}$ While ALD normally coats all surfaces similarly, area-selective deposition is possible and is an expanding field. ${ }^{10}$

Department of Chemistry, University of Oslo, Oslo, Norway.

E-mail: ola.nilsen@kjemi.uio.no

$\dagger$ Electronic supplementary information (ESI) available. See DOI: 10.1039/ d1dt00683e
Due to this flexibility in material choices and design possibilities, it is not surprising that ALD has been explored for a wide range of advanced applications like optical temperature sensors,${ }^{11}$ oxide electronics, ${ }^{12}$ and up $^{13}$ and down ${ }^{14}$ conversions, in particular when the addition of organic building blocks opens up many new technological possibilities. ${ }^{15}$ However, the range of organic components to choose from as precursors in ALD has so far been limited to quite small molecules since they need to be delivered through the gas phase.

Reviews on ALD and MLD chemistries ${ }^{7,16}$ reveal that organic precursors are quite limited beyond a single aromatic ring or a short, conjugated chain. A few examples exist where larger conjugated systems like naphthalene and biphenyl ${ }^{6}$ are used, showing near-UV activity and even visible absorption. ${ }^{17}$ These optically absorbing dye precursors require sublimation temperatures of around $250{ }^{\circ} \mathrm{C}$ or above, approaching their thermal stability. This illustrates well the difficulty in balancing Vis and NIR active optical properties with ALD/MLD compatibility.

Quinizarin (1,4-dihydroxyanthraquinone) is a well-known dye molecule, but its excellent properties are less known as an ALD/MLD precursor. This molecule belongs to the anthraquinone class of organic dyes, which show a range of optical, elec- 
<smiles>O=C1c2ccccc2C(=O)c2ccccc21</smiles>

Pentaerythritol

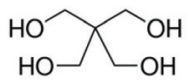

Quinizarin<smiles>O=C1c2ccccc2C(=O)c2c(O)ccc(O)c21</smiles>

Trimethylaluminium<smiles>C[Al](C)C</smiles>

Fig. 1 Anthraquinone, the parent molecule of quinizarin, and the three precursor molecules used in this work.

tronic, photocatalytic ${ }^{18}$ and red-ox properties. ${ }^{19}$ Quinizarin shows both strong visible absorption, offering large possibilities for chemical modification, and, the key point in this work, exceptionally good properties as an ALD/MLD precursor: it sublimes well at $130{ }^{\circ} \mathrm{C}$ and has good reactivity with two hydroxyl groups, and it has a rather low cost. As a metalorganic hybrid, it is explored in supercapacitors as metalorganic frameworks ${ }^{20}$ and dye sensitization of $\mathrm{TiO}_{2}{ }^{21}$ and can couple to semiconducting nanoparticles to create new lowenergy luminescent states. ${ }^{22}$ Anthraquinone, quinizarin and its derivatives have also been explored for a diverse range of uses such as eco-friendly replacement of cobalt in Li-ion batteries. ${ }^{23,24}$ In addition to red-ox activity, electronic properties and strong visible absorption, quinizarin and $\mathrm{Al}^{3+}$ ions form highly luminescent and strongly coloured complexes and polymeric structures in solutions. ${ }^{25}$ Similar properties are observed for $\mathrm{Ga}^{3+}$ and $\mathrm{In}^{3+} \cdot{ }^{26}$ The flexibility in chemical modifications and suitability as an ALD/MLD precursor allow for many exciting new avenues to be explored in the design of hybrid, organic and nanocomposite materials.

In this work, we introduce quinizarin $\left(\mathrm{H}_{2} \mathrm{Qz}\right)$ as an organic precursor in $\mathrm{ALD} / \mathrm{MLD}$ and describe the deposition of $\mathrm{Al}_{2} \mathrm{Qz}_{3}$ aluminium-quinizarin films. The growth, composition and long-term stability are explored, alongside their optical properties. Finally, as $\mathrm{Al}_{2} \mathrm{Qz}_{3}$ complexes in solution show strong visible luminescence while their dried powder counterparts do not, we attempted a "solid-state dilution" by replacing quinizarin with pentaerythritol $\left(\mathrm{H}_{4} \mathrm{Pe}\right)$, forming $\mathrm{Al}_{4} \mathrm{Pe}_{3} . \mathrm{Al}_{4} \mathrm{Pe}_{3}$ is optically passive and transparent, and its function is to increase the distance between the quinizarin molecules in the film material. With this in mind, the exploration of $\mathrm{Al}_{4} \mathrm{Pe}_{3}$ is limited to growth parameters and optical properties. The precursors used in this work and the parent anthraquinone is shown in Fig. 1.

\section{Experimental}

The films were deposited in an F-120 research-type ALDreactor (ASM Microchemistry Ltd) at $175{ }^{\circ} \mathrm{C}$. Trimethyl aluminium (TMA) (Witco GmbH, 98\%), $\mathrm{Al}(\mathrm{acac})_{3}$ (Sigma Aldrich, 99.999\%), quinizarin (Sigma Aldrich, 96\%) and pentaerythritol
(Sigma Aldrich, 98\%) were used as precursors. TMA was introduced from an external bubbler kept at room temperature, while $\mathrm{Al}(\mathrm{acac})_{3}$, quinizarin and $\mathrm{H}_{4} \mathrm{Pe}$ were sublimed at 130, 130 and $160{ }^{\circ} \mathrm{C}$, respectively. Pulse parameters (Al/purge/anion/ purge) for TMA and $\mathrm{H}_{2}$ Qz cycles were 1/1.5/3/1.5 $\mathrm{s}$, for TMA and $\mathrm{H}_{4} \mathrm{Pe}$ were $1 / 1 / 5 / 1 \mathrm{~s}$, and for $\mathrm{Al}(\mathrm{acac})_{3}$ and $\mathrm{H}_{2} \mathrm{Qz}$ were 2/1/ 2/1 s. For the $\mathrm{Al}(\mathrm{acac})_{3}$ and $\mathrm{H}_{2} \mathrm{Qz}$ depositions, both 175 and $225{ }^{\circ} \mathrm{C}$ were used as deposition temperatures. These parameters were used for the data presented in this work, while other parameters were explored.

p-Type $\operatorname{Si}(100)$ substrates cut into $0.5 \times 4 \mathrm{~cm}^{2}$ strips were used for all depositions. These were placed some $5 \mathrm{~cm}$ apart in the gas inlet and exhaust sides of the deposition chamber to monitor thickness gradients (see the photo in Fig. 6). The native oxide on the silicon substrates was not removed but was measured before deposition for every substrate. In addition, some depositions included polished steel substrates for reflection mode FTIR and amorphous silica substrates for UV-Vis measurements. All substrates were dry wiped, and dust was removed using pressurized air before deposition.

In situ quartz crystal microbalance (QCM) analyses were conducted using a $6 \mathrm{MHz}$ AT-cut quartz crystal. The crystal was mounted in a home-made holder and was used to monitor the mass increase, which is proportional to the change in the frequency, ${ }^{27}$ during the deposition to determine saturation conditions for pulse and purge parameters. The signal was recorded using a Colnatec Eon-LT system and processed by averaging over 16 consecutive ALD cycles. The temperature was stabilized for 90 minutes before any experiments were conducted to ensure a stable temperature and response from the QCM crystals.

The crystallinity of the samples was determined with a Bruker D8 Discovery X-ray diffractometer, using $\mathrm{CuK} \alpha_{1}$ radiation and a $\mathrm{Ge}(111)$ monochromator. Film thickness and refractive index were determined with a J. A. Woollam alpha-SE spectroscopic ellipsometer in the $380-900 \mathrm{~nm}$ range. The ellipsometry data were modelled using a Cauchy model. FTIR measurements were performed in the reflection mode at $75^{\circ}$ incident angle using a Bruker Vertex 70 spectrometer equipped with a Pike VeeMAX III specular reflection accessory. All data were acquired using 64 scans in the wavenumber range of $4000-370 \mathrm{~cm}^{-1}$ and at $2 \mathrm{~cm}^{-1}$ resolution. A spectrum obtained from the uncoated electropolished steel substrate was used as the background during the measurements and subtracted from the spectra of the films. The FTIR spectra of the organic precursors quinizarin and pentaerythritol were obtained from the online database Wiley SpectraBase. ${ }^{28,29}$ UV-Vis transmittance and reflectance spectra were collected with a Shimadzu UV-3600 UV-Vis-NIR spectrophotometer. Absorbance spectra were calculated from transmittance and reflectance obtained while using an integrating sphere. Luminescence (PL) measurements were performed with a $280 \mathrm{~nm}$ diode and a UV lamp (254 and $365 \mathrm{~nm}$ ) as the excitation source and a USB2000+ spectrometer from OceanOptics for detection.

X-ray photoelectron spectroscopy (XPS) was performed with a Thermo Scientific Theta Probe Angle-Resolved X-ray photo- 
electron spectrometer system using a standard monochromated $\mathrm{Al} \mathrm{K \alpha}$ source $(h v=1486.6 \mathrm{eV})$. The spectra were acquired using a pass energy of $200 \mathrm{eV}$ for survey spectra and $50 \mathrm{eV}$ for detailed peak scans with an analysis spot of roughly $400 \mu \mathrm{m}$.

\section{Results and discussion}

\section{Growth}

The $\mathrm{Al}_{2} \mathrm{Qz}_{3}$ films showed a growth rate of around $0.28 \mathrm{~nm}$ per cycle. The films showed a thickness gradient of about 33\% reduction in the growth rate over $5 \mathrm{~cm}$. This gradient was reproducible and persisted when the pulse and purge times or the precursor temperature was changed. For $\mathrm{Al}_{4} \mathrm{Pe}_{3}$, the growth rate and gradient were $0.90 \mathrm{~nm}$ per cycle and $14.3 \%$, respectively.

Fig. 2 shows the QCM response as a function of pulsing times. The observed frequency change is proportional to the mass change of the deposited material. The TMA pulse saturates at $0.2 \mathrm{~s}$. For the organic pulses, quinizarin does not show saturation even after $20 \mathrm{~s}$ pulses while pentaerythritol saturates at $10 \mathrm{~s}$. During each precursor pulse, the expected byproduct is methane from reactions between aluminium's methyl groups and the organic precursors' hydroxyl groups. For reference, the masses of the reactants and leaving molecule are: TMA = 144.18, quinizarin $\left(\mathrm{H}_{2} \mathrm{Qz}\right)=240.21$, pentaerythritol $\left(\mathrm{H}_{4} \mathrm{Pe}\right)=$ 136.15 and $\mathrm{CH}_{4}=16.04 \mathrm{~g} \mathrm{~mol}^{-1}$.

Fig. 3 shows the frequency change during each pulse and purge step for rather long pulse and purge times $(2.7 \mathrm{~s} / 10 \mathrm{~s} / 20$ $\mathrm{s} / 10 \mathrm{~s}$ for TMA/purge/organic/purge). The TMA pulse shows an immediate and rapid mass increase before reaching a plateau at about $1 \mathrm{~s}$, while the organic precursors show a much slower and longer increase in addition to a short delay in the reaction. The mass gains during each half-cycle (pulse and purge) are $\Delta f_{\mathrm{Al}}=7.39 \mathrm{~Hz}$ for TMA and $\Delta f_{\mathrm{Qz}}=10.38 \mathrm{~Hz}$ for $\mathrm{H}_{2} \mathrm{Qz}$ for $\mathrm{Al}_{2} \mathrm{Qz}_{3}$ growth, and $\Delta f_{\mathrm{Al}}=2.16 \mathrm{~Hz}$ for TMA and $\Delta f_{\mathrm{Pe}}=12.27 \mathrm{~Hz}$ for $\mathrm{H}_{4} \mathrm{Pe}$ for $\mathrm{Al}_{4} \mathrm{Pe}_{3}$ growth.

While the QCM signal does not directly reveal the chemistry taking place, it can be used to evaluate possible hypotheses.

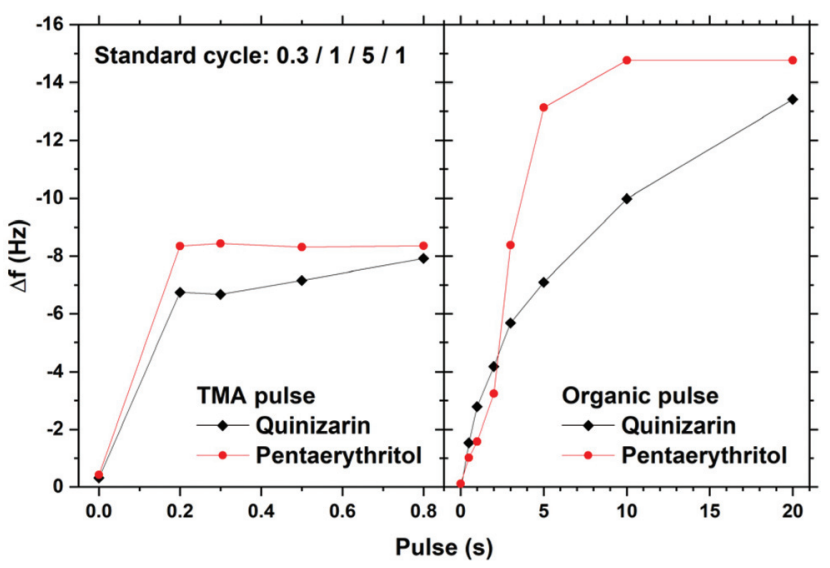

Fig. 2 QCM characterization of growth saturation as a function of pulse durations for $\mathrm{Al}_{2} \mathrm{Qz}_{3}$ and $\mathrm{Al}_{4} \mathrm{Pe}_{3}$.

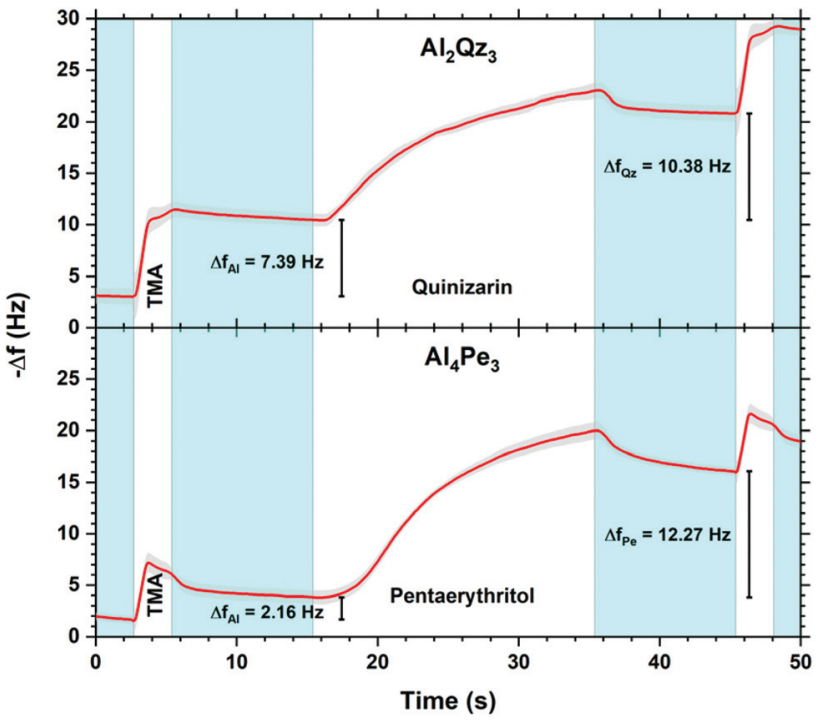

Fig. 3 Detailed QCM characterization of the growth during pulsing and purging. Pulses are marked in white and named with each respective precursor while nitrogen purges are marked in blue.

The TMA molecule should react with the Qz surface with at least one of its methyl groups. Likewise, $\mathrm{H}_{2} \mathrm{Qz}$ should react with at least one of TMA's remaining methyl groups. We use the term "should" because TMA is a strong Lewis acid, and can coordinate directly to Lewis bases without any reaction taking place, like in the pyridine-TMA complex. However, this is unlikely here due to the reactivity of the hydroxyl groups in Qz. Still, unreacted methyl groups may remain in our film after a complete cycle. If so, this will have a notable effect on the overall stoichiometry and we expect post-reactions with ambient air. If all methyl groups react, an overall stoichiometry of $\mathrm{Al}_{2} \mathrm{Qz}_{3}$ is expected, while $\mathrm{Al}\left(\mathrm{CH}_{3}\right) \mathrm{Qz}$ should form if only two methyl groups react. The latter is expected to be converted to $\mathrm{Al}(\mathrm{OH}) \mathrm{Qz}$ upon reaction with moist air. These two products can be formed by combinations of the following three halfreactions:

$$
\begin{aligned}
\mid-\mathrm{H}_{2}+2 \mathrm{Al}\left(\mathrm{CH}_{3}\right)_{3} & \rightarrow \mid-\mathrm{Al}_{2}\left(\mathrm{CH}_{3}\right)_{4}+2 \mathrm{CH}_{4} \\
\Delta m_{1} & =112.2 \\
\mid-\mathrm{Al}_{2}\left(\mathrm{CH}_{3}\right)_{4}+3 \mathrm{H}_{2} \mathrm{Qz} & \rightarrow \mid-\mathrm{Al}_{2} \mathrm{Qz}_{3}-\mathrm{H}_{2}+4 \mathrm{CH}_{4} \\
\Delta m_{2} & =656.6 \\
\mid-\mathrm{Al}_{2}\left(\mathrm{CH}_{3}\right)_{4}+2 \mathrm{H}_{2} \mathrm{Qz} & \rightarrow \mid-\mathrm{Al}_{2}\left(\mathrm{CH}_{3}\right)_{2} \mathrm{Qz}_{2}-\mathrm{H}_{2}+2 \mathrm{CH}_{4} \\
\Delta m_{3} & =448.4
\end{aligned}
$$

The mass gains during $\mathrm{H}_{2} \mathrm{Qz}$ exposure (eqn (2) and (3)) should be about 6 and 4 times larger than those during the TMA half-cycle (eqn (1)). The observed ratio in the frequency change is on the other hand closer to 1.4 (Fig. 3). This indicates that even less $\mathrm{Qz}$ is deposited per $\mathrm{Al}$ atom than what is expected from simply balancing the valency of $\mathrm{Al}^{3+}$ and $\mathrm{Qz}^{2-}$, and that neither of the most plausible reaction mechanisms are close to describing the real growth. 
A similar analysis of the QCM results for the $\mathrm{Al}_{4} \mathrm{Pe}_{3}$ film gave $\Delta f_{\mathrm{Al}}=2.16 \mathrm{~Hz}$ for TMA and $\Delta f_{\mathrm{Pe}}=12.27 \mathrm{~Hz}$ for $\mathrm{H}_{4} \mathrm{Pe}$, resulting in an observed mass ratio of ca. 6 for $\Delta f_{\mathrm{Pe}} / \Delta f_{\mathrm{Al}}$. On the basis of the overall stoichiometry of $\mathrm{Al}_{4} \mathrm{Pe}_{3}$, we combined the hypothetical reactions in eqn (4) and (5) and obtained an expected $\Delta f_{\mathrm{Pe}} / \Delta f_{\mathrm{Al}}$ value of 2.1 . This indicates that a relatively large proportion of the $-\mathrm{OH}$ groups remains unreacted during growth, and hence, the film has an excess of $\mathrm{H}_{x} \mathrm{Pe}$. A large amount of $-\mathrm{OH}$ in the deposited films will also be shown by FTIR analysis later (Fig. 5).

$$
\begin{aligned}
\mid-\mathrm{H}_{8}+4 \mathrm{Al}\left(\mathrm{CH}_{3}\right)_{3} & \rightarrow \mid-\mathrm{Al}_{4}\left(\mathrm{CH}_{3}\right)_{4}+8 \mathrm{CH}_{4} \\
\Delta m_{1} & =160.4 \\
\|-\mathrm{Al}_{4}\left(\mathrm{CH}_{3}\right)_{4}+3 \mathrm{H}_{4} \mathrm{Pe} & \rightarrow \mid-\mathrm{Al}_{4}-\mathrm{Pe}_{3}-\mathrm{H}_{8}+4 \mathrm{CH}_{4} \\
\Delta m_{2} & =344.5
\end{aligned}
$$

An $\mathrm{Al}_{2} \mathrm{Qz}_{3}$ film was investigated with XPS to determine its chemical bonding and stoichiometry. The $\mathrm{C}$ 1s peak is shown in Fig. 4, while the survey scan and $\mathrm{Al} 2 \mathrm{~s}$ and $\mathrm{O}$ 1s peaks are shown in ESI Fig. 4-6.† Fig. 4 shows 3 different carbon species, with a makeup of $75 \% \mathrm{C}-\mathrm{C}$ and about $12-13 \%$ each of $\mathrm{C}-\mathrm{O}$ and $\mathrm{C}=\mathrm{O}$. This matches well with quinizarin, having 10 out of 14 carbon atoms that are not bonded to oxygen, ideally giving $71.4 \% \mathrm{C}-\mathrm{C}$. As the film material shows distinct $\mathrm{C}-\mathrm{O}$ and $\mathrm{C}=\mathrm{O}$ species, these two oxygen atoms must bond differently to $\mathrm{Al}^{3+}$. A bidentate binding to both oxygen atoms would show up as a single carbon species in XPS instead of two distinct species. The $\mathrm{C}=\mathrm{O}$ oxygen may still participate in coordinating $\mathrm{Al}^{3+}$. The $\mathrm{Al} 2 \mathrm{p}$ peak shows that there is only one major $\mathrm{Al}$ species, indicating that all $\mathrm{Al}$ atoms are bonded similarly. The single $\mathrm{O}$ 1s peak indicates that all oxygen atoms are bonded similarly as well, i.e. to both $\mathrm{Al}$ and $\mathrm{C}$ instead of only to $\mathrm{Al}$ as in $\mathrm{Al}_{2} \mathrm{O}_{3}$. The $\mathrm{O}$ 1s peak also does not have the discrete energy

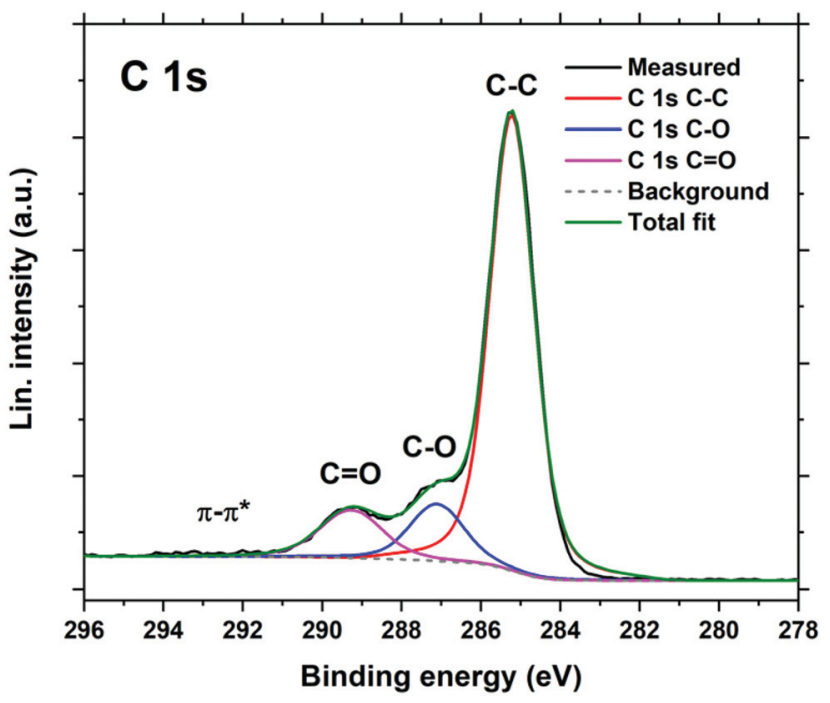

Fig. 4 XPS C 1s peak, showing contributions from three types of carbon species: $\mathrm{C}-\mathrm{C}, \mathrm{C}-\mathrm{O}$ and $\mathrm{C}=\mathrm{O}$. found for $\mathrm{Al}_{2} \mathrm{O}_{3}$. Thus, there is no indication of $\mathrm{Al}_{2} \mathrm{O}_{3}$ in the deposited material.

The atomic ratios are determined to be $5.5 \% \mathrm{Al}, 67 \% \mathrm{C}$, and $27.5 \% \mathrm{O}$, giving an overall stoichiometry of $\mathrm{AlC}_{12.2} \mathrm{O}_{5}$. The two ideal reactions eqn (1) + eqn (2) $\left(\mathrm{Al}_{2} \mathrm{Qz}_{3}\right)$ and eqn (1) + eqn (3) $\left(\mathrm{Al}\left(\mathrm{CH}_{3}\right) \mathrm{Qz}\right)$ give a stoichiometry of $\mathrm{AlC}_{21} \mathrm{O}_{6}$ and $\mathrm{AlC}_{15} \mathrm{O}_{4}$, respectively. The measured stoichiometry is close to $\mathrm{Al}\left(\mathrm{CH}_{3}\right)$ Qz, indicating a substantial amount of unreacted $\mathrm{Al}-\mathrm{CH}_{3}$ groups. As mentioned, we expect that these methyl groups react with moisture upon air exposure to form $\mathrm{Al}-\mathrm{OH}$ giving the composition $\mathrm{Al}(\mathrm{OH}) \mathrm{Qz}$, or $\mathrm{AlC}_{14} \mathrm{O}_{5}$ which is fairly close to the measured value. Thus, both XPS and QCM indicate that substantial amounts of $\mathrm{Al}-\mathrm{CH}_{3}$ groups stay unreacted during film growth.

Both QCM and XPS indicate an over-stoichiometry of Al, even compared to $\mathrm{Al}(\mathrm{OH}) \mathrm{Qz} / \mathrm{Al}\left(\mathrm{CH}_{3}\right) \mathrm{Qz}$. XPS shows that the carbonyl $\mathrm{C}=\mathrm{O}$ bond is intact in the film. Given that $\mathrm{Al}^{3+}$ is bonded to the hydroxy group and possibly only coordinated to the carbonyl oxygen, there is a possibility that some of the carbonyl groups contribute by coordinating additional TMA molecules. TMA can both coordinate to and react with carbonyl groups. ${ }^{30}$ Dandley et al. found that TMA would interact with carbonyl groups to form both $\mathrm{C}=\mathrm{O} \cdots \mathrm{Al}\left(\mathrm{CH}_{3}\right)_{3}$ adduct structures and covalent Al-O bonds at different temperatures in ALD-like vapor phase chemistry. ${ }^{33}$ This can offer a potential explanation for the apparent over-stoichiometry of $\mathrm{Al}$. However, it will require further work to elucidate this effect and the details of the growth mechanism in the TMA- $\mathrm{H}_{2} \mathrm{Qz}$ system.

Fig. 5 shows the FTIR reflectance spectra of the $\mathrm{Al}_{2} \mathrm{Qz}_{3}$ and $\mathrm{Al}_{4} \mathrm{Pe}_{3}$ films on polished steel substrates, in addition to the absorbance spectra of $\mathrm{H}_{2} \mathrm{Qz}$ and $\mathrm{H}_{4}$ Pe powders in $\mathrm{KBr}$ pellets. The broad absorption band from the $-\mathrm{OH}$ groups at $3300 \mathrm{~cm}^{-1}$ is visible in all spectra. The two peaks around $1600 \mathrm{~cm}^{-1}$ can be assigned to the carbonyl $\mathrm{C}=\mathrm{O}$ stretching of quinizarin. Xuan et al. placed the carbonyl $\mathrm{C}=\mathrm{O}$ stretching mode at $1630 \mathrm{~cm}^{-1}$. $^{31}$ ESI Fig. $3 \dagger$ shows these spectra zoomed in the $1800-500 \mathrm{~cm}^{-1}$ range. It is seen that the two carbonyl peaks are shifted to lower energies from 1630 and 1590 in the $\mathrm{H}_{2} \mathrm{Qz}$ powder to 1610 and $1580 \mathrm{~cm}^{-1}$ in the $\mathrm{Al}_{2} \mathrm{Qz}_{3}$ films.

\section{$\mathrm{Al}_{2} \mathrm{Qz}_{3}$ from $\mathrm{Al}(\mathrm{acac})_{3}$}

In an attempt to test an alternative Al-precursor, we used the same $\mathrm{Al}$-source, $\mathrm{Al}(\mathrm{acac})_{3}$, used in the solution-based work by Quinti et $a .^{25} \mathrm{Al}(\mathrm{acac})_{3}$ has previously been used for ALD to grow $\mathrm{Al}_{2} \mathrm{O}_{3} \cdot{ }^{32}$ Unfortunately, despite several attempts, we did not obtain any film when combined with $\mathrm{H}_{2} \mathrm{Qz}$. There may be many reasons for this, one of which is that bidentate acac and bidentate $\mathrm{Qz}$ form nearly identical bonds with $\mathrm{Al}^{3+}$, giving very little energy incentive for a reaction. A statistical ligand exchange between two isoenergetic ligands should still be possible if the reaction energy barrier was low. However, it seems that a solvent is necessary for this exchange to take place.

\section{Optical properties}

The $\mathrm{Al}_{2} \mathrm{Qz}_{3}$ films were deeply pink to the eye, similar to $\mathrm{H}_{2} \mathrm{Qz}-$ $\mathrm{Al}^{3+}$ solutions. Fig. 6 shows the UV-Vis transmission measure- 


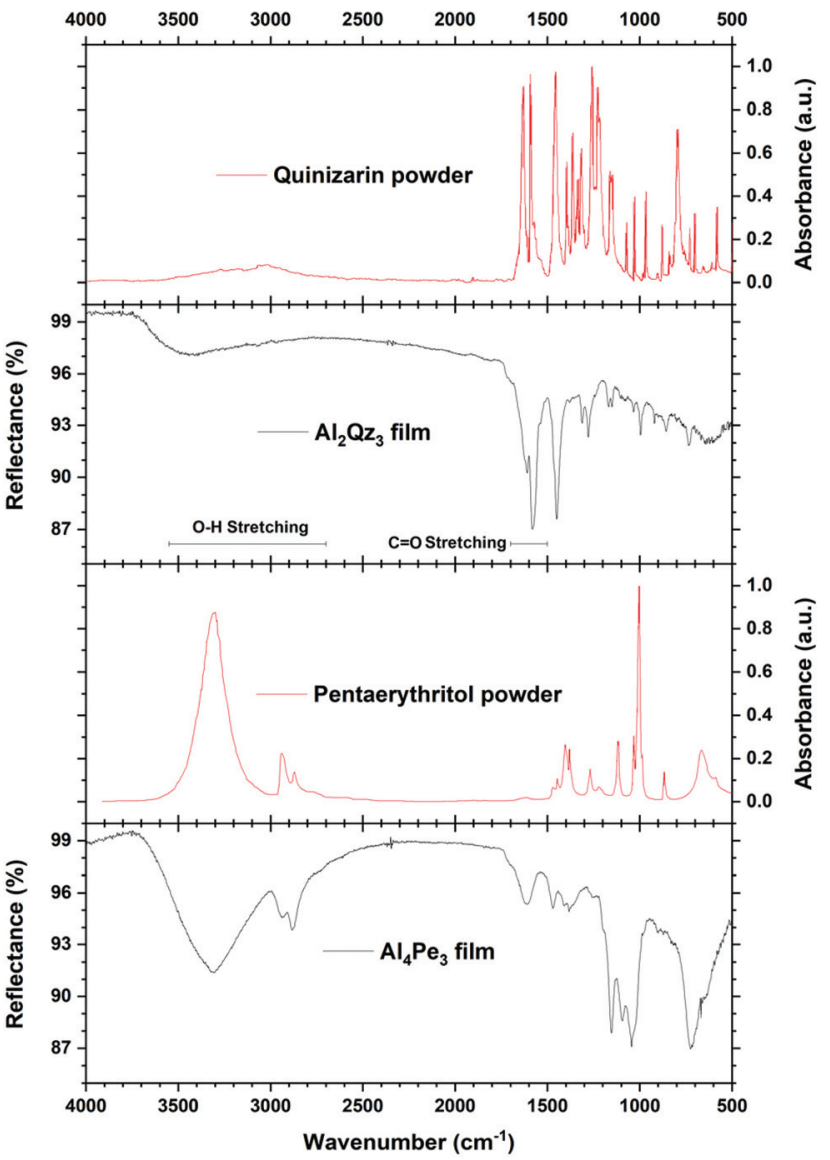

Fig. 5 FTIR data of $\mathrm{Al}_{2} \mathrm{Qz}_{3}$ and $\mathrm{Al}_{4} \mathrm{Pe}_{3}$ films on steel substrates. Quinizarin $\left(\mathrm{H}_{2} \mathrm{Qz}\right)$ and pentaerythritol $\left(\mathrm{H}_{4} \mathrm{Pe}\right)$ powders in $\mathrm{KBr}$ pellets are shown for reference, obtained from the online database Wiley SpectraBase. ${ }^{28,29}$

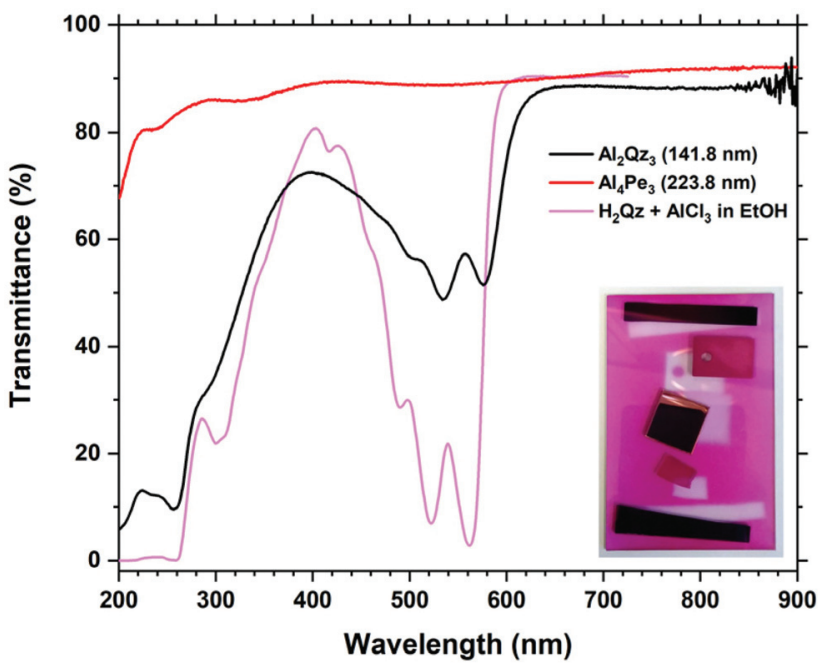

Fig. 6 UV-Vis transmission measurements of $\mathrm{Al}_{2} \mathrm{Qz}_{3}$ and $\mathrm{Al}_{4} \mathrm{Pe}_{3}$ films, both on silica substrates, and a luminescent solution of $\mathrm{H}_{2} \mathrm{Qz}$ and $\mathrm{AlCl}_{3}$ in ethanol. The photo inset shows the samples for this deposition. The gas inlet and exhaust are at the bottom and top, respectively. From the bottom, the samples are $\mathrm{Si}$, silica, steel, sintered alumina (not used in this article) and Si. ments of the $\mathrm{Al}_{2} \mathrm{Qz}_{3}$ and $\mathrm{Al}_{4} \mathrm{Pe}_{3}$ films on silica substrates, in addition to an ethanolic solution of $\mathrm{AlCl}_{3}$ and $\mathrm{H}_{2} \mathrm{Qz}$ for comparison of absorption peaks. The peak positions and shapes of $\mathrm{Al}_{2} \mathrm{Qz}_{3}$ are very similar to those of the solution, indicating that the film material is similar in optical properties to the complexes or polymeric structures formed in solution. ${ }^{25}$ These peaks are distinctly different from those of a solution containing only $\mathrm{H}_{2} \mathrm{Qz}$ without any $\mathrm{Al}^{3+}$ as shown in ESI Fig. 7. $\dagger$ The films show a blue shift in the UV range and a red shift in the visible range. The two strongest peaks in solution are shifted from 522.2 and $562.0 \mathrm{~nm}$ to 534.6 and $576.2 \mathrm{~nm}$ in the film, giving a red shift of the absorbance when $\mathrm{Al}$ is bonded to Qz. The $\mathrm{Al}_{4} \mathrm{Pe}_{3}$ film shows no absorption. Interference due to the thickness of the film is seen as waves, and the apparent drop in transparency below $240 \mathrm{~nm}$ is due to the silica substrate (Fig. 6).

Fig. 7 shows the absorbance and extinction coefficient obtained from the $\mathrm{Al}_{2} \mathrm{Qz}_{3}$ films. The optical model used for modelling the ellipsometry data is a general oscillator model with 5 Gaussian absorption peaks in the visible range. It is seen that the optical modelling fits very well with the measured absorption spectrum, showing the model's validity. The model fit to the ellipsometry data is very good, as can be seen in ESI Fig. $2 . \dagger$

\section{Dilution with pentaerythritol}

The films of $\mathrm{Al}_{2} \mathrm{Qz}_{3}$ were not luminescent as deposited. This is likely caused by concentration quenching, as also the dried powder from highly luminescent $\mathrm{Al}^{3+}+$ quinizarin solutions is non-luminescent. To overcome this, we alloyed $\mathrm{Al}_{2} \mathrm{Qz}_{3}$ with $\mathrm{Al}_{4} \mathrm{Pe}_{3}$ in $1: 8$ and $1: 19$ ratios, effectively diluting the concentration of quinizarin molecules, which are the only optically active species. Based on the growth rate of $\mathrm{Al}_{4} \mathrm{Pe}_{3}$, the separation of each $\mathrm{Al}_{2} \mathrm{Qz}_{3}$ cycle by 8 and $19 \mathrm{Al}_{4} \mathrm{Pe}_{3}$ cycles leads to an approximate Qz-Qz layer separation of 7.2 and $17.1 \mathrm{~nm}$, respectively. This should ensure that no Qz-Qz inter-layer

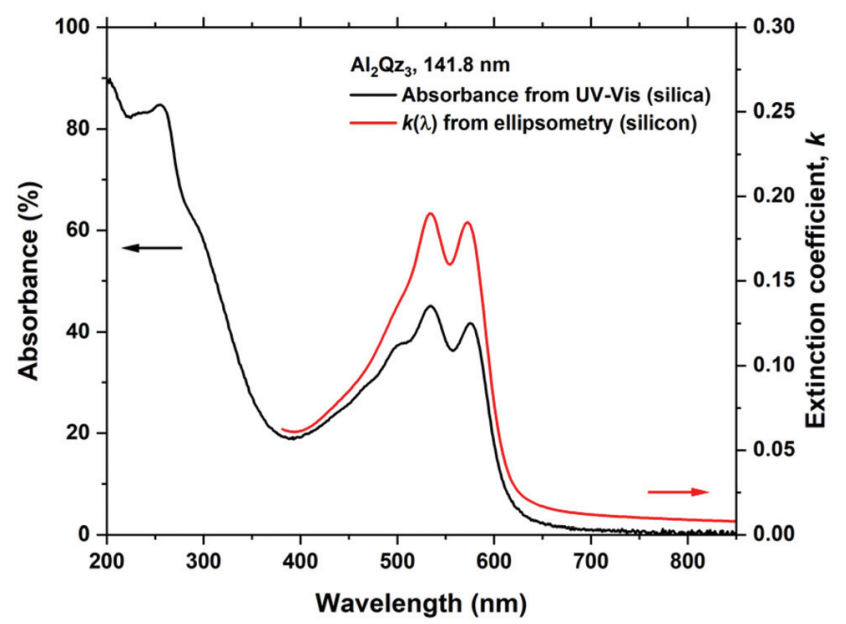

Fig. 7 Comparison of absorbance, obtained from transmittance and reflectance measurements on silica substrates, and the general oscillator optical model of the film material based on 5 Gaussian absorption peaks in the visible range. 
interaction can cause luminescence quenching. Intra-layer or in-plane Qz-Qz interactions from Qz deposited during a single $\mathrm{H}_{2} \mathrm{Qz}$ pulse are still possible. Despite such layered dilution, these films were not luminescent.

As the in-plane concentration of quinizarin resulting from a single $\mathrm{Al}_{2} \mathrm{Qz}_{3}$ cycle may be high enough to cause concentration quenching, we attempted to reduce the in-plane concentration of Qz by pulsing in $\mathrm{H}_{4} \mathrm{Pe}$ just before the $\mathrm{H}_{2} \mathrm{Qz}$ pulse. The idea was to occupy some of the TMA-terminated surface sites with $\mathrm{H}_{4} \mathrm{Pe}$, resulting in a reduced amount of Qz being deposited for each $\mathrm{H}_{2} \mathrm{Qz}$ pulse. The regular $\mathrm{H}_{2} \mathrm{Qz}$ pulse in $\mathrm{Al}_{2} \mathrm{Qz}_{3}$ depositions was replaced with an $\mathrm{H}_{4}$ Pe pulse immediately followed by an $\mathrm{H}_{2} \mathrm{Qz}$ pulse in $3 \mathrm{~s} / 1 \mathrm{~s}$ and $2 \mathrm{~s} / 2 \mathrm{~s}$ ratios. The films resulted in strong gradients in colour, from pink to transparent. Although the gradients are usually not desired, this meant that the concentration of Qz gradually reduced to zero through the sample chamber, and this sample could thus be used in a combinatorial manner. Unfortunately, no part of these films showed any luminescence. A more in-depth investigation into controlling the in-plane and inter-plane concentration of Qz is outside the scope of this work. We believe that proper control of minimum Qz-Qz distances to avoid concentration quenching could lead to the formation of luminescent $\mathrm{Al}_{2} \mathrm{Qz}_{3}$ films. This path has previously been explored in other systems, like $\mathrm{Al}^{3+}$ doped $\mathrm{ZnO}$. Learning from these prior works can be a way of finding a solution also for this hybrid system.

\section{Stability}

The rapidly increasing number of different hybrid materials that are being produced by ALD and MLD necessarily includes film materials that are air-stable, air-sensitive and anywhere in between. In this work, it is the optical properties which are in focus. Regarding stability in air, we investigated how around 7.5 months of air exposure affected the $\mathrm{Al}_{2} \mathrm{Qz}_{3}$ and $\mathrm{Al}_{4} \mathrm{Pe}_{3}$ film thicknesses in addition to the optical absorption and refractive index.

The $\mathrm{Al}_{2} \mathrm{Qz}_{3}$ films show very good stability towards air exposure, with only a $6 \%$ increase in the film thickness after 239 days (7 months, 24 days). These materials' $n(\lambda)$ and $k(\lambda)$ values were nearly unchanged as given in ESI Fig. $1, \dagger$ apart from a slight reduction in $n(\lambda)(n(632.8 \mathrm{~nm})=1.75 \rightarrow 1.73)$ and a very slight sharpening of the visible absorption peaks in $k(\lambda)$. $\mathrm{Al}_{4} \mathrm{Pe}_{3}$, on the other hand, showed more prominent swelling with a thickness increase of $22.5 \%$. The reduction in $n(\lambda)$ was similarly minute to that for $\mathrm{Al}_{2} \mathrm{Qz}_{3}, n(632.8 \mathrm{~nm})=1.57 \rightarrow 1.55$. Neither the $\mathrm{Al}_{2} \mathrm{Qz}_{3}$ nor $\mathrm{Al}_{4} \mathrm{Pe}_{3}$-diluted films showed any evolving luminescence after this air exposure.

\section{Conclusion}

In this work, we have obtained deep pink coloured films from TMA and quinizarin with a stoichiometry close to that of $\mathrm{Al}$ $(\mathrm{OH}) \mathrm{Qz}$, in addition to transparent and optically inactive films from TMA and pentaerythritol by ALD/MLD. Both QCM and XPS show an under-stoichiometry from ideal $\mathrm{Al}_{2} \mathrm{Qz}_{3}$. This is interpreted as the presence of unreacted $\mathrm{Al}-\mathrm{CH}_{3}$ groups that likely oxidize upon air exposure. An absorbance of $40 \%$ in the 500-600 nm range is obtained for a $140 \mathrm{~nm}$ thick film. Both $\mathrm{Al}_{2} \mathrm{Qz}_{3}$ and $\mathrm{Al}_{4} \mathrm{Pe}_{3}$ films are quite air-stable, showing only minor expansion and a slight reduction in the refractive index following long-term ( $>7$ months) air exposure. $\mathrm{Al}_{4} \mathrm{Pe}_{3}$ shows clear saturation during both TMA and organic pulse, resulting in a growth rate of $0.90 \mathrm{~nm}$ per cycle. $\mathrm{Al}_{2} \mathrm{Qz}_{3}$, on the other hand, does not show complete saturation during the organic pulse even for $20 \mathrm{~s}$ pulses. When deposited without saturation conditions, $\mathrm{Al}_{2} \mathrm{Qz}_{3}$ and $\mathrm{Al}_{4} \mathrm{Pe}_{3}$ show gradients in the $14-33 \%$ range over a distance of $5 \mathrm{~cm}$. The $\mathrm{Al}_{2} \mathrm{Qz}_{3}$ films are non-luminescent, even though similar $\mathrm{Al}-\mathrm{Qz}$ complexes in solution are highly luminescent. Most likely, the high density of quinizarin in the solid films causes Qz-Qz interactions and concentration quenching. We attempted to "dilute" quinizarin with $\mathrm{Al}_{4} \mathrm{Pe}_{3}$ to mitigate such concentration quenching but unfortunately did not obtain luminescent films. This work establishes quinizarin and anthraquinone derivatives as strongly absorbing visible dyes that are surprisingly well suited for ALD/MLD. This class of dye molecules includes a large range of molecules that are quite similar to quinizarin which may be similarly suited, but with a vast range of different optical and electronic properties.

\section{Author contributions}

Per-Anders Hansen: conceptualization, methodology, investigation, writing - original draft, visualization, and funding acquisition. Ola Nilsen: resources, writing - review \& editing, supervision, and funding acquisition.

\section{Conflicts of interest}

There are no conflicts to declare.

\section{Acknowledgements}

This work was performed within "The Norwegian Research Centre for Solar Cell Technology" project number 193829, a Centre for Environment-friendly Energy Research co-sponsored by the Research Council of Norway and research and industry partners in Norway. The Research Council of Norway is also acknowledged for the research project "Transition metal and lanthanide based luminescent absorber layer by ALD" with project number 244087. We also acknowledge our colleague Dr Henrik Hovde Sønsteby for performing the XPS characterization and analysis.

\section{References}

1 V. Miikkulainen, M. Leskela, M. Ritala and R. L. Puurunen, J. Appl. Phys., 2013, 113, 021301. 
2 A. J. M. Mackus, J. R. Schneider, C. MacIsaac, J. G. Baker and S. F. Bent, Chem. Mater., 2019, 31, 1142-1183.

3 H. H. Sønsteby, O. Nilsen and H. Fjellvåg, J. Vac. Sci. Technol., A, 2016, 34, 041508.

4 P.-A. Hansen, H. Fjellvåg, T. G. Finstad and O. Nilsen, Chem. Vap. Deposition, 2014, 20(7-8-9), 274-281.

5 K. B. Klepper, O. Nilsen, P.-A. Hansen and H. Fjellvåg, Dalton Trans., 2011, 40, 4636-4646.

6 K. B. Lausund, M. S. Olsen, P.-A. Hansen, H. Valen and O. Nilsen, J. Mater. Chem. A, 2020, 8, 2539-2548.

7 X. Meng, J. Mater. Chem. A, 2017, 5, 18326-18378.

8 P.-A. Hansen, T. Zikmund, T. Yu, J. N. Kvalvik, T. Aarholt, Ø. Prytz, A. Meijerink and O. Nilsen, Commun. Chem., 2020, 3, 162.

9 P.-A. Hansen, C. S. Granerød, Ø. Prytz and O. Nilsen, J. Lumin., 2019, 215, 116618.

10 J. N. Kvalvik, J. Borgersen, P.-A. Hansen and O. Nilsen, J. Vac. Sci. Technol., A, 2020, 38, 042406.

11 M. N. Getz, O. Nilsen and P.-A. Hansen, Sci. Rep., 2019, 9, 10247.

12 H. H. Sønsteby, E. Skaar, Ø. S. Fjellvåg, J. E. Bratvold, H. Fjellvåg and O. Nilsen, Nat. Commun., 2020, 11, 2872.

13 Z. Giedraityte, M. Tuomisto, M. Lastusaari and M. Karppinen, ACS Appl. Mater. Interfaces, 2018, 10, 8845-8852.

14 M. N. Getz, P.-A. Hansen, O. S. Fjellvag, M. A. K. Ahmed, H. Fjellvag and O. Nilsen, J. Mater. Chem. C, 2017, 5, 85728578.

15 H. Zhou and S. F. Bent, J. Vac. Sci. Technol., A, 2013, 31, 040801.

16 P. Sundberg and M. Karppinen, Beilstein J. Nanotechnol., 2014, 5, 1104-1136.

17 M. Tuomisto, Z. Giedraityte, L. Mai, A. Devi, V. Boiko, K. Grzeszkiewicz, D. Hreniak, M. Karppinen and M. Lastusaari, J. Lumin., 2019, 213, 310-315.
18 J. Cervantes-González, D. A. Vosburg, S. E. Mora-Rodriguez, M. A. Vázquez, L. G. Zepeda, C. Villegas Gómez and S. Lagunas-Rivera, ChemCatChem, 2020, 12, 3811-3827.

19 D. K. Palit, H. Pal, T. Mukherjee and J. P. Mittal, J. Chem. Soc., Faraday Trans., 1990, 86, 3861-3869.

20 S. Agrawal, S. M. Clarke, I. J. Vitorica-Yrezabal, C. Liu, W. Fang, P. T. Wood and D. Wright, Mol. Phys., 2019, 117, 3424-3433.

21 G. Ramakrishna, A. K. Singh, D. K. Palit and H. N. Ghosh, J. Phys. Chem. B, 2004, 108, 4775-4783.

22 S. Rawalekar, S. Verma, S. Kaniyankandy and H. N. Ghosh, Langmuir, 2009, 25, 3168-3172.

23 A. L. M. Reddy, S. Nagarajan, P. Chumyim, S. R. Gowda, P. Pradhan, S. R. Jadhav, M. Dubey, G. John and P. M. Ajayan, Sci. Rep., 2012, 2, 960.

24 V. Rajshekar Shetty, S. S. Gurukar, R. Marriappa, M. M. Kittappa and D. H. Nagaraju, New J. Chem., 2015, 39, 8534-8544.

25 L. Quinti, N. S. Allen, M. Edge, B. P. Murphy and A. Perotti, J. Photochem. Photobiol., A, 2003, 155, 79-91.

26 L. Quinti, N. S. Allen, M. Edge, B. P. Murphy and A. Perotti, J. Photochem. Photobiol., A, 2003, 155, 93-106.

27 G. Sauerbrey, Z. Phys., 1959, 155, 206-222.

28 http://spectrabase.com/spectrum/6bxGJZ9BHEf.

29 http://spectrabase.com/spectrum/24A4lKktwTw.

30 Y. Kwon, O. Scadeng, R. McDonald and F. G. West, Chem. Commun., 2014, 50, 5558-5560.

31 X. Xuan, X. Wang and N. Wang, Spectrochim. Acta, Part A, 2011, 79, 1091-1098.

32 M. Nieminen, T. Sajavaara, E. Rauhala, M. Putkonen and L. Niinistö, J. Mater. Chem., 2001, 11, 2340-2345.

33 E. C. Dandley, C. D. Needham, P. S. Williams, A. H. Brozena, C. J. Oldham and G. N. Parsons, J. Mater. Chem. C, 2014, 2(44), 9416-9424. 